\title{
Musing: Adaptable Mobile Augmented Reality Application for Museums and Art Galleries
}

\author{
Kevin Whiteside, Gentry Atkinson, Mary Mikel Stump, Dan Tamir and Grayson Lawrence \\ Texas State University \\ 601 University Dr., San Marcos, Texas, USA \\ \{kjw52, gmatkinson, mr14, dt19, gl16\}@txstate.edu
}

\begin{abstract}
A fundamental goal of museums is to engage their visitors. For the uninitiated visitor, especially for those in an academic museum or gallery, art can be challenging, intimidating, and difficult to understand. Museums have historically used text-based didactics, hardware-based audio/visual guides and on-staff docents to provide historical, technical, biographical, and sociopolitical context for artworks. In the case of small museums, inexpensive text didactics are often the only source of information available to the visitor. Hence, these venues cannot take advantage of the audio, video, Web sites, and online resources that can enhance learning. The research team has developed an iPhone application, called Musing; an Augmented Reality application that allows a museum visitor to acquire artworks images via the iPhone's camera. Using image processing algorithms, Musing recognizes the artwork and places point of interest widgets (POIs), in the form buttons, on top of the artwork displayed on-screen. These POls provide the visitor with historical, technical, biographical, and sociopolitical information via audio, video, text overlays, and/or Web sites. Placing POls over any part of an artwork allows the museum professional to provide contextual information that can help to create a meaningful experience for the visitor. The ability for the visitor to download Musing on their own phone reduces the costs associated with providing loaner hardware. Lastly, Musing's Administrator Panel allows museum professionals with limited technical ability to build exhibits and add POI for use within the application.
\end{abstract}

Interactive didactic. Museum technology. Mobile application. Image recognition. Augmented reality.

\section{INTRODUCTION}

A fundamental goal of museums is to engage and educate their visitors about the artworks and artifacts held within. For the uninitiated visitor, a lack of knowledge of art history, social, historical, geographical context, and stylistic signifiers may lead to confusion and waning interest.

Traditionally, museums provide historical, technical, biographical, and socio-political context to artworks in the form of text-based didactics, proprietary hardware audio/visual guides, and on-staff docents. Because of the extra expense in purchasing and maintaining a stable of hardware guides and staff, inexpensive textual didactics often act as the only information available to the visitor. These types of static didactics are limiting in terms of how much time the average viewer will spend reading, if at all, and they cannot take advantage of audio, video, Web sites and other online resources. As a result, opportunities for engagement with the visitor, and enhanced learning are not fully exploited.

In the last seven years, there has been a rise in the use of mobile applications to expand the variety as well as amount of didactic information supplied to visitors. Often, these applications are museumspecific and must be programmed for each exhibition by technology professionals. In many cases, museums must supply proprietary hardware for loan or install hardware in the galleries. While larger institutions have the resources to develop custom applications and supply loaner hardware to visitors, the majority of small museums do not.

\subsection{Problem Statement}

In order to create a mobile application that is useful for a wide variety of museums and galleries, an adaptable system-which allows for a wide range of online content as well as ease of implementation —should be explored.

This system should not rely on external devices installed in the gallery and should not need to be reprogrammed between exhibitions or when content changes. The system should run on readily available smartphones and tablets that many of the visitors already own. Lastly, the system should include an easy to use, administrator panel 
allowing museum professionals to input exhibition content without the need for a programmer.

The primary contribution of this research is that it describes the full implementation of both a mobile application and content administration system for museums and galleries. Musing represents a simple, effective, and, adaptive solution for museums to add interactive didactics to exhibitions.

This paper is organized in the following way: Section 2 provides a literature and state of the art review. Section 3 provides the project overview, and Section 4 details the relevance to the field of museum education. Section 5 describes the design and use of both the client application and serverside administrator panel. Section 6 discusses outcomes of the system implementation. Lastly, Section 7 outlines the conclusion and future research for the system.

\section{LITERATURE AND STATE OF THE ART REVIEW}

A literature review showed a number of teams researching the possibility of using $A R$ to augment the information provided by museum didactics.

Lawrence \& Stump (2012) developed a series of responsive Web pages, triggered by Quick Response (QR) codes for use in an exhibition for The University Galleries at Texas State. The experiment with $Q R$ codes indicated that visitors would be willing to use interactive technologies in the gallery and that they would spend the time necessary to consume the extra content. However although QR codes proved to be useful in the gallery setting, a major drawback was the inability for the museum professional to contextually place information at specific locations within the artworks, thereby missing the opportunity to speak in more specific terms about the content, context, technique, and/or meaning of the work.

Bimber \& Bruns (2011) developed a mobile application, named, PhoneGuide which allowed museum visitors to use mobile phones to detect artworks in a physical museum space. Their method included image recognition, using the phone's camera, as well as pervasive tracking techniques using a grid of Bluetooth emitters installed in the space. The reliance on Bluetooth devices to assist in the artwork recognition, however, required the museum to install new hardware in each gallery.

Blöckner et al. (2011) developed a prototype application allowing users to create virtual museum tours on a mobile app. The mobile device used near field communication (NFC) devices to transmit the tours to projectors positioned within the gallery, which displayed the desired information. As not all smartphones support NFC, this increases the need for the museum to supply loaner devices.

Miyashitat et al. (2008) developed an interactive device for the Louvre (Paris)-DNP (Dai Nippon Printing Co.) Museum Lab for use with an exhibition on Islamic Art. This device used a neural network based system to map content to exhibits and was able to recognize three dimensional objects from a single viewpoint, but also relies on proprietary hardware which is not available outside the Louvre and requires that Bluetooth hardware be installed in the gallery.

Lee \& Park (2007) used an ultra-mobile PC, inertia tracker and camera for object recognition. This image processing system did not rely on external devices. Nevertheless, the system relied exclusively on proprietary hardware supplied by the institution.

Another system that used specialized hardware to provide an augmented reality experience is described in Lee et al. (2008). The system overlays the picture of a physical image displayed on a custom device with pertinent information in realtime.

There are a number of currently available applications for visitors to download on their own devices, taking advantage of interactivity for interactive didactics, as explored below.

The Peacock Room Comes to America app, developed by the Smithsonian Institution and Arcade Sunshine Media, is an interactive iPhone and iPad app allowing users to explore artist James McNeill Whistler's Peacock Room in the Smithsonian Freer Gallery (Peacock Room Comes to America, 2014). The application allows for a virtual exploration of the space by presenting a scrolling image of the room with tap-able artworks in the scene offering expanded textual and audio information. This application does not require the visitor to be physically located within the museum to view content, as all of the information, audio and video is locally stored on the user's mobile device. This means that the application must be reprogrammed and downloaded again by the user in its entirety, if information is edited or new information is created. Musing includes a similar setting referred to as the "Permanent Exhibition." However, in addition to this option, Musing enables augmented reality and real-time/on-location user interaction with the artworks on exhibition within the galleries.

A mobile application for the Museum of Modern Art (MoMA) in New York contains a large amount of 
information about the museum, including a calendar, ability to purchase tickets, and the ability to browse the MoMA's extensive collections, either with the user physically visiting the museum or browsing at home (MoMA 2014). For educational didactics, the application allows visitors to listen to audio descriptions of artworks and view large photos of those works by typing in reference numbers located within the galleries. Much of the information is not locally stored on the device. As such, the application downloads information dynamically from the Internet. As a result, the visitor is not required to visit the museum in order to consume the information, and there is no ability to place content within the visual context of the artwork.

The McNay Art Museum in San Antonio, TX released an app called Reality Check, which allows visitors to use their device's camera to acquire artworks for recognition (Reality Check 2014). The application allows the visitor to recognize an artwork by first selecting a "clue" or shape that is present in the artwork, then use the device's camera to match that shape. Once recognized, the visitor is presented with supplemental textual, audio, and video information about the artwork. The application then stores all of the information locally on the hardware. As a result, a new version of the application must be developed as information is edited or a new exhibition is created.

The Royal Ontario Museum in Toronto, in partnership with Kensington (a production company), has released an application, called Scopify ROM, (Scopify 2014). Scopify provides rich information and interactive experience to visitors. However, the application uses QR code, which is a limiting factor in terms of visitors' utilisation (Lawrence \& Stump 2012). Additionally, this kind of application requires a great deal of work by museum staff for adding the interactive content to the artifacts. Due to the stringent requirements on content editing by technology professionals on this type of application, it is not a good fit for small museums. Due to its commercial orientation, technical information about Scopify is scarce.

While the aforementioned systems show promise, they suffer from a variety of potentially problematic issues. Some of the systems require proprietary hardware. Therefore, the museum must use financial resources to purchase and maintain loaner devices. Other systems require external devices, such as Bluetooth emitters that must be installed within the galleries. The majority of these systems require reprogramming upon each new exhibit or when content is edited. Lastly, many of the systems are highly specialized with the type of content they deliver, making them difficult to adapt to different exhibit needs.

\section{PROJECT OVERVIEW}

An interdisciplinary team of researchers from Texas State University, consisting of a Computer Scientist, a User Interface/User Experience Designer, a Museum Professional, and two Computer Science undergraduate students developed and published an iOS application, called Musing. The application was made available for download to the visitor's own smartphone or tablet (https://itunes.apple.com/us/app/musing/id6943824 $07 ? \mathrm{ls}=1 \mathrm{\& mt}=8$ ) on the Apple's iTunes store. In addition, two loaner devices were made available at the front desk for those visitors who did not own an iOS device. Moreover, the team created the Musing Administrator Panel (MAP) in order to allow for the museum professional to input curated content into the smartphone application.

The entire Musing system was implemented in two phases: Phase I tested the smartphone portion of the system using a live exhibition. Exit questionnaires were provided to visitors in order to gauge their perceptions of and responses to the application. Phase II tested MAP in a second live exhibition in order to determine its ability to provide the museum professional the opportunity to create content exhibits, add exhibition artwork images, and supply didactic information without the help from the programmers. Additionally, Phase II provided an opportunity for further testing of the smartphone portion of the system for the visitor's in-gallery experience.

\section{RELAVANCE TO THE FIELD}

Educator and innovator John Dewey spoke over a century ago of the importance of interactivity in providing for an enriched learning environment (Clapper 2010). This continues to hold true in the $21^{\text {st }}$ century museum-goer's experience. Such interactivity, and the resulting enrichment, requires addressing diverse learning styles by including visual/print, visual/picture, auditory, and verbal/kinaesthetic modalities.

As enriched learning environments are comprised of seeing, hearing, and interaction, we are able to move beyond the traditional linear model of communication that provides didactic information via textual labels and gallery talks, to a non-linear hyper-text model of communication through the provision of individual POls associated with each acquired artwork image. Through the ability of the visitor to access the POls contained within Musing, the team has created the opportunity for an enriched environment in which the visitors can partner in the making of meaning. The provision of additional information about each exhibited work via POls, as well as the action of accessing those 
POls, serves to engage the visitor.. In turn, this "solidifies the content knowledge" (Clapper 2010) by the variety of ways in which meaning is made and the ability to look at the artworks through several different filters. The individual POls provide an opportunity to show the viewer the works within an art historical, biographical, conceptual, or technical framework. As museums and galleries continue to seek means by which visitors' experiences can be augmented, these POls are a direct way to provide access to more contextual information for the exhibited works, broadening the exhibitions' theses for the novice viewer, as well as augmenting the meaning for the more initiated viewer. This extends the application's ability to meet the needs of a variety of visitors who access works on multiple levels. As such, the broadening of the exhibited works' context via interviews, videos, websites, source material, art historical influences and other art with shared conceptual frameworks, allows for a personalisation for the visitor through implied narratives (Morrisey \& Worts 1998). By deepening viewers' connections through the action of gathering the information-which can result in the visitors' "[integration of] the information into their existing world view" (Morrisey \& Worts 1998) — may be the most effective way to expand context for the works and influence the visitors' experience.

For the novice viewer, whose frame of reference may be lacking enough in depth to fully make the proper associations and connections, the POI format is perfect to expand reference points. As these associations and connections deepen, the experience looks more familiar, something that can also make looking at art more comfortable as the visitor builds on their experience. As Marjorie Schwarzer writes, "Today, when the meaning of art is more contested than ever, [technologies] offer visitors the possibility of diverse interpretations. The branches of information available on these devices are close in spirit to the multiple ways in which we engage art" (Schwarzer 2001). The ability to allow for different levels and a wide range of information, as well as a seemingly endless number of interpretive applications, reflects the diversity of the museum audience, itself (Schwarzer 2001). Ultimately, the knowledge and deepened understanding that the POIs facilitate are filtered through the learning and innovation skills of the $21^{\text {st }}$ Century - that of creativity, innovation, and crossdisciplinary thinking (Center for the Future of Museums 2008). The resulting associations within the gallery setting, moving into the viewers' world, are essential to deepening the understanding of subject matter-a result of the user transferring what he or she already knows and reflecting upon it (Clapper 2010).
Musing's effectiveness comes from the immediacy with which the user can access the POI content, the ability to "favorite" artworks and objects thereby pushing the content to their device which allows for the "capture" of content, and making information available on demand allows visitors to move freely within the space, not having to rely upon the schedule of their guide or any predetermined path.

\section{SYSTEM DESIGN}

In order to maximize adaptability of the Musing system, the team used a client/server architecture. Client/Server is a way of designing a system in which the smartphone application (client) accesses the majority of its content from a database stored on an external Web site database (server). Storing the majority of the data on a server, allows the smartphone to be updated to the most recent version content, without the need for reprogramming.

The server is managed by MAP, a Web-based administrator panel that runs in a Web browser. MAP allows the museum professional to edit and create new exhibit content, add artwork images, and assign associated POI content to those artwork images. Because of the design of MAP, the museum professional has the ability to edit all content without requiring programming or web design knowledge. This makes the system portable to many different museums with limited technical assistance.

As the Musing client is able to run on the phones of the visitors instead of proprietary hardware, this reduces the reliance on loaner hardware that the museum must provide. In addition, Musing uses only the device's camera for artwork recognition, meaning there is no reliance on external devices (e.g. Bluetooth, NFC, or QR). The only requirement of the museum is to provide WIFI access, for devices with no wireless access or in situations where the building's architecture blocks cellular signals.

All of these advantages make Musing a reasonable system to implement in a museum setting, with limited technical knowledge on the part of the museum professional and minimal cost of implementation.

\subsection{The smartphone client}

After downloading Musing, the visitor is presented with the Home Screen (Figure 1a), which enables browsing of all exhibits available for viewing. This screen also acts as an avenue for museums to advertise their exhibitions. 
The Home Screen is divided into Permanent Exhibits and Augmented Reality Exhibits. Permanent Exhibits allow users to view selected artworks and POls without visiting the gallery and serves as an introduction to the kind of supplemental information they would see in situ with an exhibition. When the user chooses a Permanent Exhibit, they are presented with a listview of artworks allowing immediate consumption of the information associated with POls. By contrast, the Augmented Reality Exhibit, activates the devices' camera and instructs the visitor to capture a physical artwork image in the gallery. Musing enabled artworks are denoted by a small Musing logo, placed near the artwork.

Once acquired by the visitor, Musing compares the photo taken by the camera with reference images that are retrieved when the visitor chooses an exhibit. Musing displays the identified image of the artwork, along with its associated POI (figure 1b). If the image recognition fails, the user is asked to fill the entire screen with the image and retake the photo.

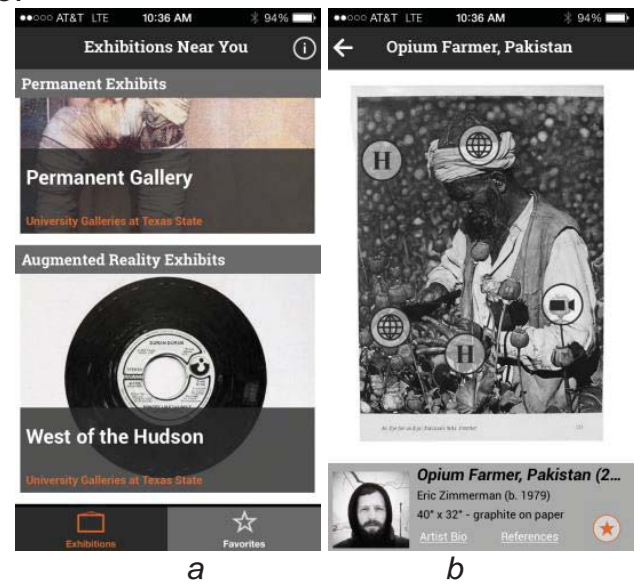

Figure 1a: Musing home screen; Figure 1b: View Artwork screen with artist information, Bio and Reference links, and Favourite button. History, Web and Video POI types visible

The museum professional has the ability to place a variety of different types of POIs, superimposed over an artwork. The POI types include History, Web site, Video, Factoids (short textual information) (Figure 2a), and Technique. The POls display representative icons, informing the user of the expected subject matter typologies.

Musing's ability to display many types of Web content, allows the museum professional to choose from a variety of educational resources. The museum professional, may choose to generate original content, shared via a Web page for one of the $\mathrm{POI}$, or they may decide to provide a link to an existing Web site that provides the information (Figure 2b).
In addition to Web pages, and textual information, the museum professional is able to link the $\mathrm{POI}$ to existing formats such as YouTube or Vimeo (Figure 3a).

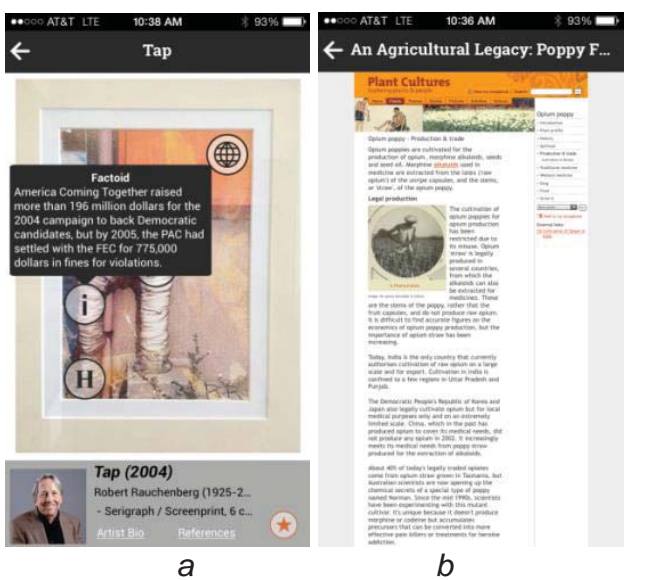

Figure 2a: Factoid POI; Figure 2b: External website

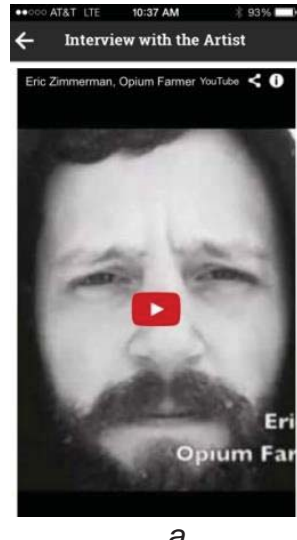

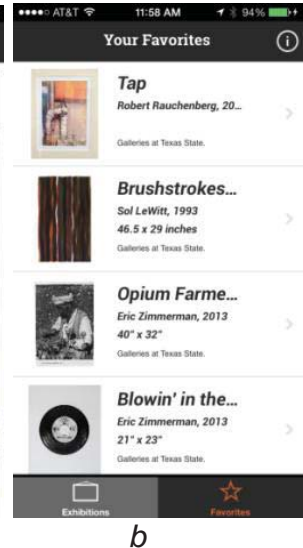

Figure 3a: YouTube video, created and uploaded by the musing professional; Figure 3b: Favourites screen with list-view of saved artworks

Placing $\mathrm{POI}$ in the exact portion of the artwork desired allows the museum professional to provide spatially correlated context to the information to which the POI links, thus enhancing the ability for the user to understand different aspects of the artwork, the artist(s) who created it, its historical significance, and techniques used in its making

Finally, the user has the ability to favorite an artwork, by pressing the star-shaped button in the lower right-hand corner (Figure 1b), for later viewing of the information (Figure $3 b$ ).

\subsection{Musing administrator panel}

One of the most important aspects of the Musing system is that of MAP, which provides the museum professional with the ability to easily edit and add new content to the system.

MAP is a Web site, allowing the museum professional to add, edit, and delete content from 
the database that feeds the Musing smartphone application. Without MAP, the Musing system would require expensive upkeep by programmers.

There are 4 main areas of the administrator panel: Exhibits, Artworks, Edit POI, and Artists.

The Exhibits page, allows the user to create/add exhibits, edit and delete existing exhibits (figure 4). From this page, the user is able to select existing exhibits for editing as well as create new ones.

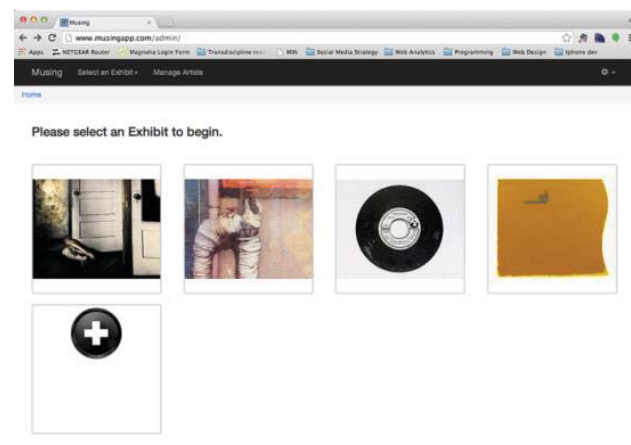

Figure 4: Exhibits page, showing existing exhibits

When the user adds a new exhibition, MAP launches the Edit Exhibition page (Figure 5). This interface allows the user to browse their local machine for an exhibition image (automatically resized by the system), choose a beginning and end date for the exhibit, enter the museum or gallery name and set the exhibit type to Permanent or Augmented Reality. The information collected is displayed in Musing's Home Screen (figure 1a).

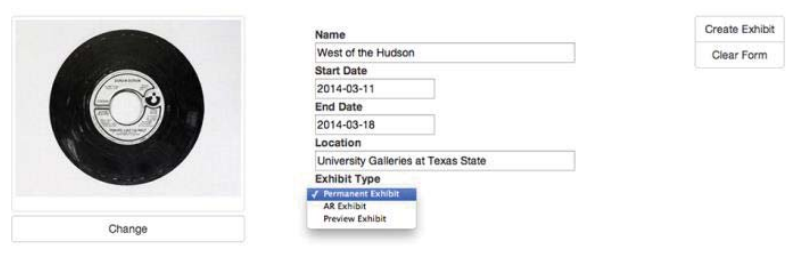

Figure 5: Adding a new exhibit (detail)

After a new exhibit is created, the user is taken to the Artworks page. This page allows the user to add new artwork images, to the exhibition or edit existing artworks within the exhibition (Figure 6).

Adding a new artwork is done on the Artworks page. This page allows the user to upload and crop a reference photo of the artwork (used for image recognition by the smartphone app), and enter information about the artwork. This information may include the artwork's title, dimensions, materials, year created and the artist's name, all displayed in Musing for the visitor after image recognition has taken place (Figures $1 \mathrm{~b}$ and $2 \mathrm{a}$ ).
From the selected artwork's page, the user is able to edit the POI (Figure 7). When in this mode, the user is able to add new POI, place the POI on the image by clicking and dragging, assign content, and choose one of the POI categories: History, Technique, Information, Web, or Video. The POls are assigned $X, Y$ coordinates and appear in Musing in the same locations (Figures 1a and 2b).

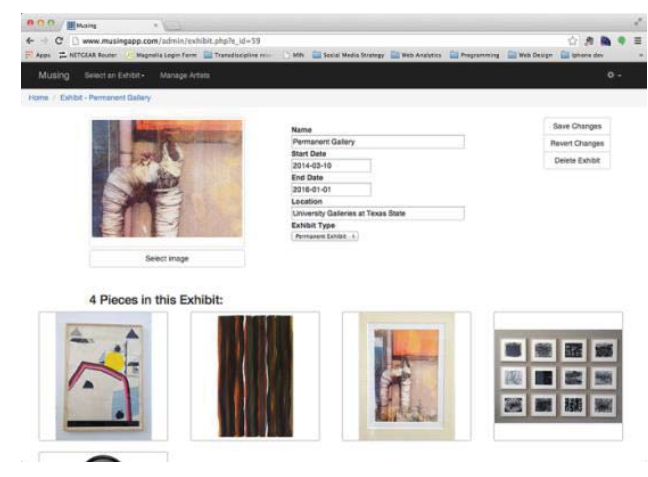

Figure 6: Managing artworks within an exhibit

Artist information is kept separate from the exhibits and the individual artworks to avoid duplication of data entry. The Artist section of MAP allows the user to add new artists or edit existing (Figure 8).

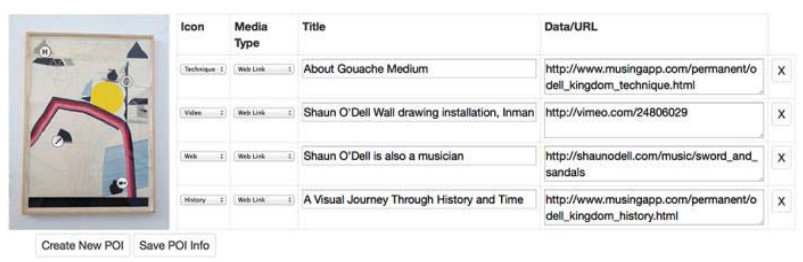

Figure 7: Editing POI on the artwork (detail)

Editing the artist allows the user to upload and crop a headshot of the artist, input their name, birth/death dates, and links to their biographies, as well as bibliographic references. This biographic information is displayed in Musing at the bottom of the View Artworks Screen (figure 1b).
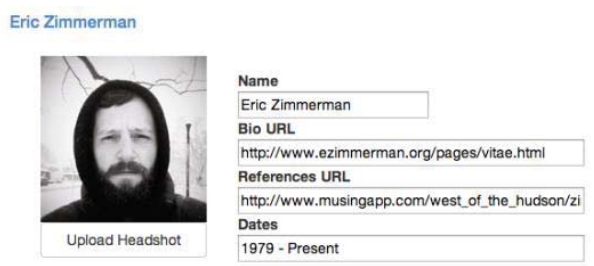

Update Artist Delete Aritist

Figure 8: Editing Artist information (detail)

\section{IMPLIMENTATION AND RESULTS}

Musing was implemented in two phases. Phase I was primarily concerned with the testing of the Musing client, while Phase II primarily tested MAP. 
Prior to launching Musing, the research team performed experiments to assess the image recognition capabilities of the app. A recognition rate of $96.4 \%$ was verified under ideal conditions, with the user standing in front of the artwork, with no camera rotation. Under less-than-ideal conditions, testing indicated that Musing recognizes images at a 45 degree rotation with $90 \%$ reliability and a 90 degree rotation with $84 \%$ reliability (Atkinson et al. 2014). Based on this information, the team has concluded that the recognition rate is well suited for providing a satisfactory user experience. Additional technical details and information concerning these experiments is available in Atkinson et al. (2014).

\subsection{Phase I}

The Musing client was deployed from October $8^{\text {th }}$, to November $14^{\text {th }}, 2013$ in the University Galleries at Texas State University, for Eric Zimmerman: West of the Hudson (Musing enabled images are available at:

http://www.musingapp.com/test images/).

An optional exit questionnaire was provided to gallery visitors. Questions were written in a Likert format and were designed to garner perceptions on usability, accuracy of image recognition, and other visitor feedback.

During the 38 day exhibit, 242 (25\%) visitors downloaded Musing, with 49 choosing to answer an exit questionnaire. Visitor feedback was positive, as $89.8 \%$ felt the application helped them to understand the artworks and $93.8 \%$ indicated they would like to see Musing used in future exhibits. $61 \%$ of users felt that the amount of content provided was "just enough". This data points to a high acceptance rate for Musing and the content chosen for the exhibit.

$91.8 \%$ of respondents own smartphones, with $85.7 \%$ owning iOS devices and $12.2 \%$ owning Android phones. Only 11 visitors opted to use a loaner device.

This data suggests that very few visitors needed to borrow a device, but that an Android version of Musing should be developed in order to be available to the widest array of visitors.

\subsection{Phase II}

The second trial of musing was a test of MAP as well as a continued test of the smartphone portion of the application-specifically, the image recognition capabilities of Musing. In order to test for a wider array of information, the second trial used two exhibitions. The first was an exhibition of photographs by artist, Lauren E. Simonutti, titled:
The Devil's Alphabet. The second exhibit, Richard Martinez: ¡PAINTINGSFORNOW!, was chosen because of the artworks' strong silhouettes and limited amount of detail, which could further test the abilities of the client application's image recognition. Testing in the gallery indicated that the imagery in The Devil's Alphabet was fully recognisable by Musing. However, Musing's recognition rate of artworks in iPAINTINGSFORNOW! was not satisfactory. This exhibition was then offered as a Permanent exhibit. It is theorized that the flat colour and limited amount of detail in the artworks were to blame for the failure. This points to a need to enhance the image recognition capabilities of Musing by enabling the fusing of information obtained from procedures that fit different types of artwork.

Prior to using MAP for the first time, the museum professional was given a 30 minute walk-through. This walk-through included instruction on creating a new exhibit, adding a new artwork and placing a number of different POI. The museum professional was then tasked with creating content for the two new exhibitions with limited assistance.

The museum professional was able to successfully place almost all of the content into the application via MAP interface. MAP allowed for uploading of the reference images, placing the $\mathrm{POI}$ with their associated Video, Audio, Factoid textual information, and external Web pages.

One area that proved difficult was lengthy textual information that could not fit into the more limited Factoid POI type. These pieces of information needed to be added to the system by WordPress CMS to create a Web page that could be linked to a POI. In future versions of MAP, a more robust text editor will be added.

\section{CONCLUSIONS AND FUTURE RESEARCH}

The implementation of the Musing client in three exhibits continue to show promise for the system's ability to provide contextual didactic information on a commercially available mobile device, without the need for hardware installed in the gallery, and without the need for reprogramming between exhibits.

Phase II's exhibitions showed some limitations with Musing's image recognition methodologies when faced with artworks containing minimal visual detail.

Results of testing MAP indicated the interface was useful enough to create new exhibits, add artwork images, and create POls to provide audio, video, textual, and Web didactic information. However, the 
reliance on an external system (WordPress) to create longer textual information indicated the need for further enhancements to MAP in the form of a visual editor.

Additional research and development related to the image recognition algorithm will be required in order to improve Musing's ability to recognize a wide variety of artworks, including those with limited visual detail. The ability to recognize 3D objects, will also broaden the appeal for museums.

Finally, the entire system should be implemented in a variety of independent museums in order to further test the viability of the system.

\section{REFERENCES}

Atkinson, G., Whiteside, K., Tamir, D. E., Lawrence, G., Stump, M. (2014) Musing: interactive didactics for art museums and galleries via image processing and augmented reality., Content 2014, Venice, Italy May 25-29 (accepted for publication). International Journal on Advances in Intelligent Systems.

Bimber, O. and Bruns, E. (2011) PhoneGuide: adaptive image classification for mobile museum guidance, IEEE International Symposium on Ubiquitous Virtual Reality, Jeju, South Korea, 2011, pp.1-4.

Blöckner, M., Danti, S., Forrai, J., Broll, G., and De Luca, A. (2011) Please touch the exhibits!: using NFC-based interaction for exploring a museum, International Conference on Human-Computer Interaction with Mobile Devices and Services, New York, 2011, Article 71.

Clapper, T.C. (2010) The enriched environment: making multiple connections, The Academic Leadership Journal, 8, Fall. Retrieved from http://www.academia.edu/1180002/The Enriched

Environment Making Multiple Connections

(retrieved 20 March, 2014).

Center for the Future of Museums, American Association of Museums, Washington, DC. (2008) Museums \& Society 2034: Trends and Potential Futures, (December 2008, v.1).

http://resource.aaslh.org/view/museums-andsociety-2034-trends-and-potential-futures-report/. (retrieved 18 March 2014).

Lawrence, G. and Stump, M. (2012) Connecting physical and digital worlds: a case study of quick response codes and social media in a gallery setting, The International Journal of Design in Society, 6(3), pp. 79-95.

Lee, D. and Park, J. (2007) Augmented Reality based Museum Guidance System for Selective Viewings, IEEE Workshop on Digital Media and its Application in Museum \& Heritage, Chongign, China, pp. 379-382.

Miyashitat, T., Meier, P., Tachikawa, T., Orlic, S., Scholz, V., Gapel, A., Gerl, O., Arnaudov, S., and Lieberknecht, S. (2008) An augmented reality museum guide, IEEE International Symposium on Mixed and Augmented Reality, Cambridge, UK, pp. 103-106.

MOMA iPhone application. https://itunes.apple.com/us/app/moma/id38399045 $\underline{5 ? \mathrm{mt}=8}$ (retrieved 18 March 2014).

Morrissey, K. and Worts, D. (1998) A place for the muses? Negotiating the role of technology in museums. In S. Thomas and A. Mintz (Eds.), The virtual and the Real: Media in the Museum (pp. 147-171). Washington, D.C.: American Association of Museums.

Oh, J., Lee, M., Park, H., Park, J., Kim, J., and Son, W. (2008) Efficient Mobile Museum Guidance System Using Augmented Reality, IEEE International Symposium on Consumer Electronics, Vilamoura, Portugal, pp. 1, 4, 14-16.

Peacock Room Comes to America iPhone and iPad application.

https://itunes.apple.com/us/app/peacock-roomcomes-to-america/id671150763?mt=8 (retrieved 18 March 2014).

Reality Check iPhone application. https://itunes.apple.com/us/app/themcnay-realitycheck/id615135643?mt=8 (retrieved 18 March 2014).

Rublee, E., Rabaud, V., Konolige, K. and Bradski, G. (2001) ORB: an Efficient Alternative to SIFT or SURF, IEEE International Conference on Computer Vision, Barcelona, Spain, pp. 2564-2571.

Scopify. http://scopify.com (retrieved 18 March 2014).

Schwarzer, M. (2001) Art \& Gadgetry: The Future of the Museum Visit, Museum News, July/August. http://www.aam-us.org/pubs/mn/MN JA01 ArtGadgetry.cfm (retrieved 29 November 2011). 